\title{
Correction to: Joint report on the terminology for surgical procedures to treat stress urinary incontinence in women
}

Developed by the Joint Writing Group of the American Urogynecologic Society and the International Urogynecological Association

Published online: 9 May 2020

(C) The International Urogynecological Association 2020

Correction to: International Urogynecology Journal (2020) 31:465-478

https://doi.org/10.1007/s00192-020-04237-0

In this publication, there was an error with the authorship in which Veronica Valderrama was listed as an author. The correct authorship for the Joint Writing Group should be as follows:

Sarah A. Collins, Steven Swift, Swati Jha, Anna Rosamilia, Renaud de Tayrac 